\title{
MÉTODOS ESTRATÉGICOS GERAIS PARA ESTUDOS DA INFORMAÇÃO NO CONTEXTO VIRTUAL
}

\author{
GENERAL STRATEGIC METHODS FOR STUDIES OF INFORMATION IN THE VIRTUAL \\ CONTEXT
}

Ruleandson do Carmo Cruz ${ }^{1}$

${ }^{1}$ Doutor em Ciência da Informação pela Universidade Federal de Minas Gerais (UFMG).

E-mail: ruleandson@gmail.com

\section{A ACESSO ABERTO}

Copyright: Esta obra está licenciada com uma Licença Creative Commons Atribuição 4.0 Internacional. $(\mathrm{cc}) \mathrm{EY}_{\mathrm{EY}}$

Conflito de interesses: 0 autor declara que não há conflito de interesses.

Financiamento: Não há.

Declaração de Disponibilidade dos dados: Todos os dados relevantes estão disponíveis neste artigo.

Recebido em: 24/04/2019.

Revisado em: 01/05/2019.

Aceito em: 10/05/2019.

\section{Como citar este artigo:}

CRUZ, Ruleandson do Carmo. Métodos estratégicos gerais para estudos da informação no contexto virtual. Informação em Pauta,

Fortaleza, v. 4, n. especial, p. 10-25, maio 2019. DOI: https://doi.org/10.32810/25253468.ip.v4iEspecial.2019.41206.10-25.

\section{RESUMO}

Aborda-se métodos estratégicos qualitativos gerais para estudo da informação no contexto virtual. Define-se pesquisa qualitativa, informação e o contexto virtual de produção e circulação da informação. Traça-se estratégias para articulação entre objetivos de pesquisa e procedimentos metodológicos afim de alcançarse os resultados, respondendo ao problema de pesquisa. Conclui-se que o estudo da informação em contextos virtuais requer criatividade metodológica.

Palavras-chave: Métodos. Internet. Estudos de usuários.

\section{ABSTRACT}

General qualitative strategic methods are studied for the study of information in the virtual context. It defines qualitative research, information and the virtual context of information production and circulation. Strategies are articulated between research objectives and methodological procedures in order to reach the results, responding to the research problem. We conclude that the study of information in virtual contexts requires methodological creativity.

Keywords: Methods. Internet. User studies. 


\section{INTRODUÇÃO}

O estudo dos sujeitos informacionais no contexto virtual da informação, especialmente no âmbito da produção e da circulação da informação em sites e aplicativos voltados à formação de redes sociais virtuais requer um esforço no referente ao desenho da pesquisa, pois os métodos e procedimentos de coleta e análise de dados ainda são insuficientes para a investigação de um cenário recente no campo das pesquisas científicas, como o campo das redes virtuais.

Hodiernamente, sabe-se que dos cerca de 7,4 bilhões de pessoas que vivem no mundo (CRIADO, 2016), pelo menos dois bilhões são usuários mensais do site voltado à formação de redes sociais virtuais Facebook e 800 milhões de pessoas nele curtem postagens diariamente - ação de demonstrar ter gostado da informação compartilhada por outro sujeito informacional usuário do referido site (AGÊNCIA BRASIL, 2017). Destarte, o Facebook é apenas um das dezenas de sites do tipo existentes e nos quais sujeitos de diversas partes do planeta criam e compartilham, socializam, informações. Na contemporaneidade, o acesso a e a navegação em sites de redes sociais são as atividades mais comuns dos internautas mundiais (CISCO, 2017), sendo que, especialmente no Brasil, os sujeitos costumam passar, em média, 650 horas por mês navegando em redes sociais (COMSCORE, 2015).

Assim, no presente artigo, sugere-se alguns métodos estratégicos gerais que o pesquisador no campo da Ciência da Informação - CI e áreas correlatas, ao realizar pesquisas qualitativas, pode adotar para desenhar a pesquisa e ir dos objetivos aos resultados com mais assertividade.

\section{SUJEITO INFORMACIONAL E INFORMAÇÃO ENQUANTO ARTEFATO CULTURAL}

Como sugestão geral de desenho de pesquisa, o presente artigo recomenda que os pesquisadores considerem nos estudos da informação no contexto virtual os conceitos de sujeito informacional, práticas informacionais e informação enquanto artefato cultural. Na CI, o sujeito em contato com a informação costuma ser entendido como usuário da informação: inicialmente, usuário-público, com características sociodemográficas, interage com dado sistema ou serviço de informação; posteriormente, é central o 
entendimento do sujeito por meio de um tripé necessidade-busca-uso (PINHEIRO, 1982; LE COADIC, 1996). Por tal tripé, o usuário é um sujeito que, por uma necessidade informacional, converte-se em usuário da informação, ao lidar com a informação (NÚÑEZ PAULA, 2004, p. 24). Mas, tais entendimentos enfrentam críticas no campo. Duas das mais fortes são as de Day (2011) e Réndon-Rojas e García Cervantes (2012), na qual emerge o termo sujeito informacional.

De acordo com Day (2011), é preciso que o campo da CI demarque a morte do termo usuário da informação, por ser ele teoricamente inadequado para a compreensão dos aspectos sociais, culturais e físicos dos indivíduos e das relações dos sujeitos com os afetos e poderes de tais aspectos. Também faz-se importante frisar-se que, ao pensar em usuário da informação, segundo o autor, foca-se na pesquisa que visa determinar causas e efeitos durante o processo de busca por informação. Assim, é preciso, mais do que isso, "visualizar sujeitos e objetos como co-emergências mediadas através de codeterminações contextuais e por meio de zonas comuns de afetos mútuos [relacionais]" (DAY, 2011, p. 86, tradução nossa).

Assim, em considerável semelhança a entendimentos da problemática apontada por Day (2011), surgem ideias divergentes ao termo usuário da informação. Neste contexto, abordagens em ascensão nas pesquisas em CI, conceituam e entendem os usuários enquanto sujeitos sociais que mantém relações com a informação, de acordo com Araújo (2013).

A relação entre sujeito e objeto informacional é a premissa básica para se entender o sujeito informacional, de acordo com Rendón-Rojas e García-Cervantes (2012), que introduzem o conceito de sujeito informacional.

\footnotetext{
É neste contexto que se dá a emergência do sujeito informacional, em um cenário que condiciona, mas ao mesmo tempo permite ao sujeito interpelar para demandar, construir e articular novas estruturas socioinformativas, para atuar nessa conjuntura social.

Perante este fenômeno social, se reafirma que as identidades não se impõem, se constroem; são produto das relações sociais complexas (RENDÓN-ROJAS e GARCÍA-CERVANTES, 2012, p. 36-37, tradução nossa).
}

Dessa forma, só se faz sentido pensar em um sujeito informacional em um contexto social, contexto no qual a informação apresenta-se enquanto artefato cultural. discutir o funcionamento informacional da cultura, Marteleto (1995) tece algumas observações a 
respeito do "processo de construção da idéia de informação como artefato cultural, como forma de criação e instituição dos significados ou ainda como modo de produção, controle e distribuição social dos bens simbólicos" (online). Assim, a autora aborda a cultura informacional nesses aspectos, buscando entender a funcionalidade da informação no âmbito social e histórico e sem relação com o entendimento da cultura informacional dado por Davenport (2000).

Para aprofundar tal discussão, Marteleto (1995, online) define - no contexto de seu entendimento da cultura informacional - a cultura como "conjunto de artefatos construídos pelos sujeitos em sociedade (palavras, conceitos, técnicas, regras, linguagens) pelos quais dão sentido, produzem e reproduzem sua vida material e simbólica" e a informação enquanto derivada da cultura como algo que "diz respeito não apenas ao modo de relação dos sujeitos com a realidade, mas também aos artefatos criados pelas relações e práticas sociais [...] uma probabilidade de sentido" (online).

A autora frisa que cultura e informação são conceitos e fenômenos interligados naturalmente, pois a cultura é a depositária da informação social, pois, por meio dos padrões culturais, a cultura funciona como modelo para organização dos processos sociais e psicológicos. Desse modo, os padrões culturais (religioso, filosófico, estético, científico ou ideológico) tornam-se fontes de informação através das quais a vida humana pode ser padronizada (GEERTZ, 1978 , p. 188 apud Marteleto, 1995, online). Um dos pontos principais desses processos, para Marteleto (1995, online), é que "a cultura é o primeiro momento de construção conceitual da informação, como artefato, ou como processo que alimenta as maneiras próprias de ser, representar e estar em sociedade".

Acerca do funcionamento da cultura, Marteleto (1995, online) pondera ser ele um modo de funcionamento social-histórico. Os artefatos culturais são produzidos e reproduzidos através de sua institucionalização na sociedade, efetivada, em primeiro plano, mediante a coerção e as sanções e, em segundo plano, pela adesão, o apoio, a legitimidade e a crença. Assim, a cultura é social e histórica, pois os artefatos culturais e os próprios indivíduos são criações culturais e históricas, que dão coesão à sociedade comportando-se como um tecido imenso e complexo de significações (CASTORIADIS, 1987 , p. 229 apud MARTELETO, 1995, online).

Tais significações, de acordo com Marteleto (1995), desenvolvem-se sempre em duas dimensões, a dimensão conjuntista-identitária e a dimensão propriamente 
imaginária. Nesse sentido, entende-se por dimensão conjuntista-identitária o modo como "a sociedade opera, agindo e representando, por meio de elementos, classes, propriedades e relações tidos como distintos e definidos [...] o funcionamento da sociedade, das instituições e dos significados pode ser determinado e controlado" (CASTORIADIS, 1987, p. 235-236 apud MARTELETO, 1995, online). Por sua vez, na dimensão propriamente imaginária, "o esquema dominante é o da significação. Posto que as significações podem ser demarcadas, mas não determinadas, uma vez que elas se conectam umas às outras como uma cadeia infinita e não previsível) (CASTORIADIS, 1987, p. 235 apud MARTELETO, 1995, online).

Marteleto (1995) frisa também que a informação enquanto forma e dinâmica cultural é uma "forma instituída de memória, gestão, distribuição e recepção dos artefatos culturais, é aqui o elemento de ligação entre as dimensões conjuntista-identitária e imaginária, que regem o funcionamento da 'instituição total da sociedade' e da própria dinâmica cultural" (online). O resultado é que os artefatos culturais somente são produzidos e reproduzidos pelo modo informacional, pois toda prática social é uma prática informacional, compreendida como os "mecanismos mediante dos quais os significados, símbolos e signos culturais são transmitidos, assimilados ou rejeitados pelas ações e representações dos sujeitos sociais em seus espaços instituídos e concretos de realização" (MARTELETO, 1995, online).

Nessa perspectiva, Bordieu (1980) apud Marteleto (1995, online) lembra que, nas sociedades contemporâneas, a perda de poder da aristocracia e da Igreja resulta na constituição e fortalecimento de campos relativamente autônomos de produção e reprodução cultural, como os campos sociais artístico, filosófico, científico e educacional, bem como os campos sociais de distribuição e consumo como editoras, bibliotecas, arquivos, museus e a indústria cultural. Tal situação propicia a atual existência de um mercado de oferta e de consumo dos bens culturais. Ressalta-se ainda que os bens culturais produzidos como matéria informacional são distribuídos socialmente e não compartilhados, pois são dependentes das instâncias de produção, reprodução, transmissão e aquisição (MARTELETO, 1995, online).

Para a autora, o funcionamento dos campos sociais integra as condições de produção, transmissão e aquisição dos bens culturais, sendo que tais condições são representantes dos mecanismos que situam emissores-transmissores-receptores, assim como integra também os objetos, valores e sentidos que acompanham as informações. No 
entanto, segundo Marteleto (1995), os campos sociais não criam uma totalidade, devido à separação entre produtores e receptores dos bens culturais "por critérios de saber e de poder, que, em última instância, dizem respeito à acessibilidade aos campos e aos seus significados, [o que] supõe e repõe incessantemente as diferenças e os conflitos sociais" (MARTELETO, 1995, online). Nesse cenário cultural, a informação, para a autora, organiza as relações sociais - dispersas e conflituais - e dá aparência de dispersão e neutralidade ao conhecimento racional - produzido como se fosse homogêneo e indivisível.

$\mathrm{Na}$ mesma perspectiva social, surgem os chamados estudos das práticas informacionais. Para Savolainen (2007), a ideia de prática informacional nasce nos anos 1960, mas ainda é pouco usada no campo da CI, em comparação ao uso do conceito de comportamento informacional. De acordo com Araújo (2007; 2013), o conceito de prática informacional é oriundo do conceito de prática usado pela etnometodologia - estudo dos métodos pelos quais os indivíduos dão sentido às suas ações - e permite estudar os sujeitos informacionais considerando as facetas sociais da produção de conhecimento.

Assim, Savolainen (2007) afirma: "comparado com o modelo de comportamento informacional, o conceito de prática informacional adota como papel central os aspectos sociais e culturais enquanto fatores determinantes e qualificantes da busca por informação e compartilhamento de informação pelos sujeitos" (SAVOLAINEN, 2007, p. 125, tradução nossa). Destarte, o autor frisa que tanto o comportamento informacional quanto as práticas informacionais focam-se no modo como o sujeito lida com a informação, apesar disso, o comportamento informacional entende o lidar com a informação como sendo desencadeado por motivos e necessidades, enquanto a prática informacional entende que o lidar com a informação relaciona-se com a continuidade e a habitualização de ações moldadas e afetadas pelo social e pelo cultural (SAVOLAINEN, 2007).

\section{PESQUISA QUALITATIVA EM CIÊNCIA DA INFORMAÇÃO}

Este artigo demarca-se enquanto sugestão de métodos estratégicos para a pesquisa social qualitativa. Para Bauer, Gaskell e Allum (2008), a pesquisa social é a que se apoia em dados sociais resultantes e produzidos nos processos de comunicação, 
divididos em dois modos de dados sociais: comunicação formal e comunicação informal, que podem ser produzidos em três meios, texto, imagem e som. De acordo com os autores, o modo de dados sociais de comunicação informal é gerado quando o pesquisador interessa-se por "como as pessoas espontaneamente se expressam e falam sobre o que é importante para elas e como elas pensam sobre suas ações e a dos outros" (p. 21), sem a exigência de um conhecimento especializado como se dá com os dados sociais de comunicação formal.

Ao analisar a metodologia para a pesquisa social, Minayo (2009, p. 21) afirma que o objeto das ciências sociais é essencialmente qualitativo, por tratar-se dos conjuntos das expressões humanas presentes nas estruturas, processos, representações sociais, expressões da subjetividade, símbolos e significados. Assim, a autora pondera que a pesquisa qualitativa nas Ciências Sociais se ocupa com o universo da produção humana, que dificilmente pode ser traduzido em números e/ou indicadores quantitativos.

Segundo Flick (2009, p. 16), a pesquisa qualitativa não possui modelos precisos, por isso, uma de suas principais características e necessidades é o princípio da adequação como orientador na pesquisa qualitativa: "os métodos devem ser adequados àquela questão e devem ser abertos o suficiente para permitir um entendimento de um processo ou relação".

Do mesmo modo que a pesquisa qualitativa, a pesquisa em CI também não possui uma metodologia específica e deve atentar-se à adequação das estratégias metodológicas à problemática em estudo, pois, conforme ressalta González de Gomez (2000, online), a CI apresenta-se desde seu início "como conjunto de saberes agregados por questões antes que por teorias". Com isso, a autora observa que

Quando são abordadas as práticas e ações de informação [como na presente pesquisa], devemos usar estratégias comunicacionais seja para reconstruir a produção de sentido dos atores sociais, seja para construir e interpretar indicadores operacionalizados sobre produtos e resultados observáveis das ações de informação. 0 acesso comunicacional aos fenômenos culturais da informação requer estratégias metodológicas descritivas, interpretativas, próprias da antropologia, a sociolinguística, os estudos sociais da ciência, entre outras (GONZÁLEZ DE GOMEZ, 2000, online).

Para a objetivação e produção do conhecimento no campo da CI, associam-se princípios conceituais e metodológicos diferentes. Assim, González de Gomez (2000) sugere que no estudo das ações de informação dos atores sociais considere-se a seguinte associação entre conceitos e metodologia de pesquisa, conforme ilustra o QUADRO 1. 
QUADRO 1 - Metodologia de pesquisa social aplicada à CI

\begin{tabular}{|c|c|c|c|}
\hline $\begin{array}{l}\text { Estratos } \\
\text { informacionais }\end{array}$ & Modalidades & $\begin{array}{l}\text { Formas de ação/ } \\
\text { operação }\end{array}$ & $\begin{array}{l}\text { Condições de } \\
\text { produção do } \\
\text { conhecimento }\end{array}$ \\
\hline $\begin{array}{l}\text { Informação } \\
\text { (semântica) }\end{array}$ & $\begin{array}{l}\text { Modos intersubjetivos de } \\
\text { significação; definição } \\
\text { cultural e social de uma } \\
\text { evidencia ou "testemunho" } \\
\text { de informação, suas } \\
\text { condições de geração, de } \\
\text { transmissão, de recepção e } \\
\text { de adesão }\end{array}$ & $\begin{array}{l}\text { Ações abertas e } \\
\text { plurais/ polimórficas, } \\
\text { conforme } \\
\text { diferenciais } \\
\text { semânticos / } \\
\text { pragmáticos dos } \\
\text { atores }\end{array}$ & $\begin{array}{l}\text { Conhecimento } \\
\text { antropológico- } \\
\text { linguístico } \\
\text { (Regras/ } \\
\text { usos/práticas) }\end{array}$ \\
\hline
\end{tabular}

FONTE: Adaptado de González de Gomez (2000, online).

Assim, ao estudar-se o estrato informacional relacionado à produção subjetiva da informação, como na presente pesquisa, o objeto da CI deve ser considerado como a “construção de significado de segundo grau a partir das práticas e ações sociais de informação, que constituem seu domínio fenomênico" (GONZÁLEZ DE GOMEZ, 2000, online).

Destarte, considerado o supracitado, o pesquisador deve definir o desenho da pesquisa. Para Flick (2009), o desenho da pesquisa qualitativa evidencia como serão coletadas e analisadas as evidências que possibilitarão ao pesquisador responder às perguntas da investigação em curso, sendo composto pela amostragem, comparação pretendida (indicação das dimensões e níveis em que se pretende fazer comparações comparar grupos ou pessoas ou situações específicas entre si), generalização pretendida, questões relativas à qualidade, públicos e escrita, triangulação, e limitação do foco, para tornar a pesquisa exeqüível.

Assim, sugere-se no presente artigo que o estudioso da informação no contexto das redes sociais virtuais adote o desenho geral de pesquisa dos estudos devido a adequação às características gerais de tal estratégia de pesquisa. conforme observa Yin (2005), tal estratégia é válida à pesquisa social porque nela não se pode controlar eventos comportamentais, portanto, só pode-se estudá-los observando-se os acontecimentos e/ou realizando-se entrevistas com as pessoas neles envolvidos (YIN, 2005, p. 26-27). Segundo o autor:

estudos de casos representam a estratégia preferida quando se colocam questões do tipo 'como' e 'por que', quando o pesquisador tem pouco controle 
sobre os acontecimentos e quando o foco se encontra em fenômenos contemporâneos inseridos em algum contexto da vida real [...] a clara necessidade pelos estudos de caso surge do desejo de se compreender fenômenos sociais complexos [...] o estudo de caso permite uma investigação para se preservar as características holísticas e significativas dos acontecimentos da vida real (YIN, 2005, p. 19-20).

Segundo Martins (2008), o estudo de caso é uma estratégia de pesquisa que exige análise qualitativa, por ter como objetivo o estudo aprofundado e intensivo de uma unidade social (um caso), pesquisada dentro de seu contexto real, onde o pesquisador não tem controle sobre eventos e variáveis, mas busca a apreensão total da realidade de uma situação para descrevê-la, compreendê-la e interpretá-la diante de sua complexidade.

De acordo com Yin (2005), os estudos de casos dividem-se em estudos de caso único e em estudos de casos múltiplos. Assim, o estudo de caso único consiste no estudo de uma única unidade, que deve ser escolhida quando um caso representa o caso decisivo para se testar uma teoria bem formulada, ou trata-se de um caso raro ou extremo, representativo ou típico (YIN, 2005, p. 62-63), enquanto o estudo de casos múltiplos consiste no estudo de mais de um caso único no mesmo estudo de caso, sendo que cada caso selecionado deve servir a um propósito diferente (YIN, 2005, p. 68). Como a presente pesquisa não possui subsídios para tratar uma única comunidade do Orkut como caso decisivo, opta-se pela realização de um estudo de casos múltiplos, no qual cada comunidade virtual em estudo representará um caso único.

Para Yin (2005), o estudo de caso pode ainda ser holístico ou incorporado. Com isso, o estudo holístico de caso se dá quando se analisa a natureza global de um evento, programa ou organização (YIN, 2005, p. 65), enquanto o estudo incorporado de caso ocorre quando dentro de um caso único (ou de cada caso único em um estudo de casos múltiplos) se dá atenção a uma subunidade ou a várias subunidades, cada uma podendo utilizar técnicas diferentes de coleta de dados (YIN, 2005, p. 64-65). Como no presente estudo se dará atenção a subunidades (comportamento informacional, cultura informacional, redes sociais, representações sociais e informação sobre amor) em cada caso (comunidade virtual) opta-se por um estudo incorporado de casos múltiplos.

Sob a ótica metodológica, Martins (2008, p. xii) diz que um estudo de caso deve ser "precedido pela exposição do problema de pesquisa - questões orientadoras - do enunciado de proposições - teses - que compõem a teoria preliminar que será avaliada a partir dos achados da pesquisa; de uma plataforma teórica". 0 autor destaca ainda a importância de se apresentar um detalhado planejamento de toda a pesquisa, por meio 
do protocolo do estudo de caso, que deve conter: "descrição dos instrumentos de coleta de dados e evidências, estratégias de coleta e análise dos dados, possíveis triangulações de dados, prováveis encadeamentos de evidências e avaliações da teoria previamente admitida" (MARTINS, 2008, p. xii).

Dento de tal desenho de pesquisa enquanto estudo de caso, o pesquisador deve estar atento ao papel da revisão de literatura na pesquisa. Para Yin (2005), a revisão de literatura (ou revisão teórica) tem como objetivo criar um referencial teórico ou plataforma teórica para subsidiar a análise a ser realizada pela pesquisa e a teoria a ser desenvolvida por ela. Com isso, Yin (2005, p. 28) observa que a revisão teórica em um estudo de caso é "um meio para se atingir uma finalidade, e não - como pensam muitos estudantes - uma finalidade em si”. Assim, considerando-se Gil (2009), a revisão de literatura para compor o referencial teórico do presente estudo considera a pesquisa bibliográfica e a pesquisa documental: a) pesquisa bibliográfica) para Gil (2009), a pesquisa bibliográfica contempla a revisão de livros e artigos científicos que permitem ao pesquisador cobrir fenômenos mais amplos do que se imagina de início, dando base teórica para a fase de análise de tais fenômenos; b) pesquisa documental) segundo Gil (2009), assemelha-se à pesquisa bibliográfica, no entanto, sua maior diferença está na natureza das fontes, pois tal pesquisa é formada por materiais que ainda não passaram por tratamento analítico, ou que podem ser reelaborados segundo os objetivos da pesquisa. De acordo com o autor, há os documentos de primeira mão, que ainda não foram tratados analiticamente, como: documentos oficiais, reportagens de jornal, cartas, filmes, fotografias etc.; e os de segunda mão, que foram analisados de alguma forma, como: relatórios de pesquisa; relatórios de empresas; tabelas estatísticas etc.

Além da revisão de literatura, em uma pesquisa social qualitativa na qual se utiliza o desenho de estudo de caso, há ainda teoria descritiva a ser desenvolvida. Acerca da teoria a ser desenvolvida em um estudo de caso, pondera-se que tal teoria tem o objetivo de ser um esquema suficiente para o estudo, bem como o de determinar quais dados devem ser coletados e as estratégias de análise desses dados (YIN, 2005, p. 49-51). Sob ótica similar, Martins (2008, p. 11-12) constata que tal teoria busca "explicações e interpretações convincentes para situações que envolvam fenômenos sociais complexos" e "inferências analíticas sobre proposições constatadas no estudo e outros conhecimentos encontrados". 
Dentre as possibilidades de teoria a serem desenvolvidos, Yin (2005) destaca o desenvolvimento de uma teoria descritiva em um estudo de caso, teoria essa que deve: a) voltar-se ao propósito descritivo de responder a questões sobre como se configura determinado fenômeno; b) ser ampla, mas realista no sentido de exequível, considerandose uma variedade de tópicos que podem ser considerados como uma descrição do que se estuda; c) apontar prováveis tópicos que serão a essência da descrição (ver as categorias de análise dessa pesquisa, f. 186-188). Para o autor, o objetivo é o de "generalizar um conjunto particular de resultados a alguma teoria mais abrangente" (YIN, 2005, p. 58).

Dessa maneira, neste artigo sugere-se aos pesquisadores estudiosos da informação no contexto da informação produzida e circulante em ambientes virtuais que dediquem os estudos, de forma inicial, ao desenvolvimento de uma teoria descritiva sobre como se configuram as práticas informacionais e a informação enquanto artefato cultural dos sujeitos informacionais em estudo.

Para essa tarefa em específico, realiza-se duas etapas do estudo de caso: as questões orientadoras (questões de estudo a serem respondidas pela pesquisa científica), e as proposições teóricas (substitutas das hipóteses comumente formuladas em pesquisas científicas), sendo que "cada proposição direciona a atenção a alguma coisa que deveria ser examinada dentro do escopo do estudo". Segundo Martins (2008), tais proposições teóricas são

formuladas a partir de algum conhecimento do caso e reflexões do pesquisador [...] podem ser entendidas como uma teoria preliminar, criada pelo autor, que buscará, ao longo do trabalho, defender e demonstrar. Ou seja, a explicitação de uma teoria acerca do caso, anterior à coleta de qualquer dado ou evidências [...] substituem os objetivos e as hipóteses normalmente formuladas nas pesquisas convencionais (MARTINS, 2008, p. 68).

Para o desenvolvimento da referida teoria descritiva o pesquisador pode (ou deve) valer-se de uma estratégia básica recomendada sempre em bancas de qualificação pela professora Adriana Bogliolo: 1) criar um primeiro quadro associando objetivos de pesquisa (questões orientadoras em estudos de casos) e categorias de análise (categorias advindas do referencial teórico da pesquisa e que vão subsidiar a análise); 2) criar um segundo quadro no qual o pesquisador associe categoria de análise com procedimentos metodológicos e principais teorias associadas para a análise qualitativa. Sugere-se isso, pois é comum o pesquisador ficar em dúvida sobre quais dados deve coletar e como deve analisar tais dados. Assim, uma forma de clarificar tal processo é construindo um quadro 
relacionando cada objetivo da pesquisa e pensando em quais procedimentos metodológicos ele deve utilizar para conseguir coletar tais dados.

A seguir apresenta-se tais quadros sem serem aplicados a uma pesquisa e na sequência os quadros já aplicados a um estudo de mestrado (CRUZ, 2011).

QUADRO 2 - Questões orientadoras e categorias de análise

\begin{tabular}{ll}
\hline Questão orientadora & Categorias de análise \\
\hline $\begin{array}{l}\text { Questão orientadora um (questionamento secundário } \\
\text { que se constitui enquanto etapa necessária para se } \\
\text { responder ao problema de pesquisa) }\end{array}$ & $\begin{array}{l}\text { Categoria advinda do referencial teórico da } \\
\text { pesquisa e que permita analisar os dados } \\
\text { qualitativamente e responder a tal questão } \\
\text { orientadora }\end{array}$ \\
$\begin{array}{l}\text { Questão orientadora dois (questionamento secundário } \\
\text { que se constitui enquanto etapa necessária para se } \\
\text { responder ao problema de pesquisa) }\end{array}$ & $\begin{array}{l}\text { Categoria advinda do referencial teórico da } \\
\text { pesquisa e que permita analisar os dados } \\
\text { qualitativamente e responder a tal questão } \\
\text { orientadora }\end{array}$ \\
$\begin{array}{l}\text { Questão orientadora três (questionamento secundário } \\
\text { que se constitui enquanto etapa necessária para se }\end{array}$ & $\begin{array}{l}\text { Categoria advinda do referencial teórico da } \\
\text { pesquisa e que permita analisar os dados } \\
\text { qualitativamente e responder a tal questão } \\
\text { orientadora }\end{array}$ \\
\hline
\end{tabular}

Fonte: Autor com base nas orientações de Adriana Bogliolo

QUADRO 3 - Categorias de análise por procedimentos metodológicos e principais teorias associadas

\begin{tabular}{|c|c|c|}
\hline Categoria de análise & Procedimentos metodológicos & $\begin{array}{l}\text { Principais teorias } \\
\text { associadas (para a } \\
\text { análise qualitativa) }\end{array}$ \\
\hline $\begin{array}{l}\text { Categoria de análise um } \\
\text { (categorias advindas do } \\
\text { referencial teórico da } \\
\text { pesquisa e que vão subsidiar } \\
\text { a análise, classificando e } \\
\text { agrupando os dados conforme } \\
\text { o nome da categoria, } \\
\text { referente ao conteúdo } \\
\text { qualitativo dos dados). }\end{array}$ & $\begin{array}{l}\text { Quais procedimentos permitirão } \\
\text { encontrar os dados qualitativos } \\
\text { necessário para a análise desta } \\
\text { categoria? Entrevistas? } \\
\text { Questionários? Análise de redes } \\
\text { sociais? Análise documental? Etc. }\end{array}$ & $\begin{array}{l}\text { Quais autores } \\
\text { apresentados (AUTOR, } \\
\text { ANO) apresentados no } \\
\text { referencial teórico da } \\
\text { pesquisa vão permitir a } \\
\text { análise dos dados } \\
\text { coletados nesta categoria? }\end{array}$ \\
\hline Categoria de análise dois & Procedimentos associados & Autores associados \\
\hline Categoria de análise três & Procedimentos associados & Autores associados \\
\hline
\end{tabular}

Fonte: Autor com base nas orientações de Bogliolo

Apresentados os modelos gerais desenhados pelo autor com base nas orientações de Bogliolo, traz-se, na sequência, a aplicações dele em pesquisa de mestrado que 
objetivou estudar a representação do amor em sites de redes sociais, ressalta-se que a referenciada pesquisa foi produzida em 2011, antes do autor adotar os conceitos de sujeito informacional e práticas informacionais aqui sugeridos, o que não desmerece os quadros enquanto exemplos metodológicos.

QUADRO 4- Questões orientadoras e categorias de análise

\begin{tabular}{|c|c|}
\hline Questão orientadora & Categorias de análise \\
\hline $\begin{array}{l}\text { Como o amor é representado socialmente pelos } \\
\text { usuários/atores em estudo? }\end{array}$ & Representação social do amor. \\
\hline $\begin{array}{l}\text { Como os usuários/atores em análise constroem seu } \\
\text { perfil no Orkut em relação à informação sobre amor? }\end{array}$ & Perfil informacional amoroso. \\
\hline $\begin{array}{l}\text { Como os usuários/atores em estudo lidam com a } \\
\text { informação sobre amor? }\end{array}$ & Comportamento informacional. \\
\hline $\begin{array}{l}\text { Como as comunidades virtuais em análise promovem } \\
\text { e/ou controlam a criação e compartilhamento da } \\
\text { informação sobre amor? }\end{array}$ & Cultura informacional. \\
\hline $\begin{array}{l}\text { Como se configura o fluxo informacional da informação } \\
\text { sobre amor nas redes sociais virtuais de informação } \\
\text { sobre amor em análise? }\end{array}$ & $\begin{array}{l}\text { Redes sociais virtuais de informação sobre } \\
\text { amor. }\end{array}$ \\
\hline $\begin{array}{l}\text { Como as comunidades virtuais em estudo definem-se na } \\
\text { rede?; }\end{array}$ & $\begin{array}{l}\text { Redes sociais virtuais de informação sobre } \\
\text { amor; Representação social do amor. }\end{array}$ \\
\hline $\begin{array}{l}\text { Como se configuram as redes sociais formadas pelos } \\
\text { usuários/atores em investigação?; }\end{array}$ & $\begin{array}{l}\text { Redes sociais virtuais de informação sobre } \\
\text { amor. }\end{array}$ \\
\hline $\begin{array}{l}\text { Qual o papel das redes sociais virtuais de informação } \\
\text { sobre amor em análise para os usuários/atores em } \\
\text { estudo? }\end{array}$ & $\begin{array}{l}\text { Redes sociais virtuais de informação sobre } \\
\text { amor; Representação social do amor. }\end{array}$ \\
\hline
\end{tabular}

Fonte: CRUZ (2011) 
QUADRO 5 - Categorias de análise por procedimentos metodológicos e principais teorias associadas

\begin{tabular}{|c|c|c|}
\hline Categoria de análise & Procedimentos metodológicos & $\begin{array}{l}\text { Principais teorias } \\
\text { associadas (para a } \\
\text { análise qualitativa) }\end{array}$ \\
\hline Representação social do amor. & $\begin{array}{l}\text { Análise documental (fóruns, } \\
\text { enquetes e tópicos); entrevistas } \\
\text { (usuários/atores nós ativos). }\end{array}$ & $\begin{array}{l}\text { Aristóteles (2000); } \\
\text { Bauman (2004); Brandão } \\
\text { (1993); Costa (1999); } \\
\text { Grimal (1993); Platão } \\
\text { (1991); Moscovici } \\
\text { (2007b); Morin (2009). }\end{array}$ \\
\hline Perfil informacional amoroso. & $\begin{array}{l}\text { Análise documental (perfis e } \\
\text { tópicos); questionários } \\
\text { (usuários/atores nós ativos); } \\
\text { entrevistas (usuários/atores nós } \\
\text { ativos e donos e/ou moderadores). }\end{array}$ & $\begin{array}{l}\text { Aguiar (2007); Bauman } \\
\text { (2004); Costa (1999); } \\
\text { Recuero (2009b); } \\
\text { Marteleto e Tomaél } \\
\text { (2005); Martí (2000). }\end{array}$ \\
\hline Comportamento informacional. & $\begin{array}{l}\text { Análise documental (tópicos e } \\
\text { perfis); questionários } \\
\text { (usuários/atores nós ativos); } \\
\text { entrevistas (usuários/atores nós } \\
\text { ativos); } \\
\text { ARS. }\end{array}$ & $\begin{array}{l}\text { Davenport (2000); } \\
\text { Marteleto e Tomaél } \\
(2005) \text {; Recuero }(2009 \mathrm{~b}) ; \\
\text { Wilson }(1997,2000) .\end{array}$ \\
\hline Cultura informacional. & $\begin{array}{l}\text { Análise documental (fórum e } \\
\text { tópicos); entrevistas (donos e/ou } \\
\text { moderadores); } \\
\text { ARS. }\end{array}$ & $\begin{array}{l}\text { Davenport (2000); } \\
\text { Recuero (2009b); } \\
\text { Marteleto e Tomaél } \\
\text { (2005); Martí-Lahera } \\
\text { (2003); Nahl (2007a). }\end{array}$ \\
\hline $\begin{array}{l}\text { Redes sociais virtuais de } \\
\text { informação sobre amor. }\end{array}$ & $\begin{array}{l}\text { ARS; softwares de visualização de } \\
\text { redes; análise documental (perfis e } \\
\text { tópicos; questionários } \\
\text { (usuários/atores nós ativos); } \\
\text { entrevistas (usuários/atores nós } \\
\text { ativos e donos e/ou moderadores). }\end{array}$ & $\begin{array}{l}\text { Baruchson-Arbib (1996); } \\
\text { Bauman (2003); } \\
\text { Haythornthwaite (1996); } \\
\text { Marteleto e Tomaél } \\
\text { (2005); Recuero (2009b); } \\
\text { Ribas e Ziviani (2008); } \\
\text { Schultz-Jones (2009); } \\
\text { Widén-Wulff et al. (2008). }\end{array}$ \\
\hline
\end{tabular}

Fonte: Autor

\section{CONSIDERAÇÕES FINAIS}

O desenho da pesquisa qualitativa é um dos principais desafios tanto para os pesquisadores em geral no campo da CI quanto para os que especificamente dedicam-se ao estudo das informações no contexto virtual. Dessa forma, a proposta do presente artigo foi aplicada com êxito em dois estudos de fôlego e alta complexidade (CRUZ 2011; CRUZ 2014), o que faz com que se creia no êxito de tais sugestões.

Quando o pesquisador entende claramente a relação entre as categorias de análise, os procedimentos metodológicos e o referencial teórico que subsidiará a análise ele se 
foca no que é necessário para se alcançar os objetivos da pesquisa, sem entregar um estudo que não se relacione ao problema de pesquisa e sem gastar tempo e energia desnecessários para entender como coletar e analisar dados. A ideia dos quadros aqui apresentados é facilitar tal processo ao se estudar as práticas informacionais de sujeitos informacionais imbricados na produção e socialização de informações no contexto virtual. Frisa-se que as sugestões aqui apresentadas são gerais, em outro trabalho focou-se em sugestões especificas para o estudo da informação nos sites de redes sociais virtuais (CRUZ; 2018).

\section{REFERÊNCIAS}

ARAÚJO, Carlos Alberto Ávila. O sujeito informacional no cruzamento da Ciência da Informação com as Ciências Sociais. XIV, ENANCIB, 2013, Florianópolis, SC. In: XIV Encontro Nacional de Pesquisa em Ciência da Informação, 14., 2013, Florianópolis, SC. Anais [...]. Florianópolis, SC: XIV ENANCIB, 2013. Disponível em:

http://enancib.sites.ufsc.br/index.php/enan cib2013/XIVenancib/paper/viewFile/142/2 6. Acesso em: 01 nov. 2013.

BAUER, Martin W.; GASKELL, George; ALLUM. Nicholas C. Qualidade, quantidade e interesses do conhecimento - evitando confusões. In: BAUER, Martin W.; GASKELL, George (Org.). Pesquisa qualitativa com texto, imagem e som: um manual prático. Petrópolis: Vozes, 2008. p. 17-36.

CISCO. The zettabyte era: trends and analysis. Cisco, Solutions, Write pappers, 7 jun. 2017. Disponível em: http://www.cisco.com/c/en/us/solutions/c ollateral/service-provider/visualnetworking-index-vni/vnihyperconnectivity-wp.html. Acesso em 14 jul. 2017.

COMSCORE. Futuro digital em foco 2015.

ComScore, 2015. Disponível em: http://www.comscore.com/por/layout/set/ popup/Request/Presentations/2015/2015Global-Digital-Future-in-Focus. Acesso em 14 jul. 2017.
CRIADO, Miguel Ángel. 10 bilhões de pessoas povoarão a Terra em 2053. El País, Demografia, 25 ago. 2016. Disponível em: https://brasil.elpais.com/brasil/2016/08/2 5/ciencia/1472108333_340880.html. Acesso em: 14 jul. 2017.

CRUZ, Ruleandson do Carmo. Cultura informacional e distinção: a orkutização sob o olhar social da Ciência da Informação. Tese. (Doutorado em Ciência da Informação) Universidade Federal de Minas Gerais, Escola de Ciência da Informação, Belo Horizonte, 2014. Disponível em: http://ruleandson.blogspot.com/2014/11/c ultura-informacional-e-distincao.html. Acesso em: 28 abr. 2019.

CRUZ, Ruleandson do Carmo. Proposta teórico-metodológica para o estudo de sujeitos informacionais usuários de sites de redes sociais virtuais. Revista Brasileira de Educação em Ciência da Informação, v.5, n.1, p.47-62, jan./jun. 2018. Disponível em: https://drive.google.com/file/d/1yYePXG8e 29vUGZWMtG1ftm4pi70eDU4T/view?usp=s haring. Acesso em: 2 set. 2018.

CRUZ, Ruleandson do Carmo. Redes sociais virtuais de informação sobre amor: comportamento e cultura informacional de usuários do Orkut, 2011. Dissertação (Mestrado em Ciência da Informação) Universidade Federal de Minas Gerais, Escola de Ciência da Informação, Belo Horizonte, 
2011. Disponível em:

http://ruleandson.blogspot.com/2011/06/r edes-sociais-virtuais-de-informacao.html. Acesso em: 28 abr. 2019.

\section{DAVENPORT, Thomaz H. Ecologia da}

informação: porque só a tecnologia não basta para o sucesso da era da informação. São Paulo: Futura, 2000.

DAY, Ronald E. Death of the user: reconceptualizing subjects, objects, and their relations. Journal of the American Society for Information Science and Technology, Silver Spring, v. 62, n. 1, p. 7888, 2011. Disponível em: http://onlinelibrary.wiley.com/doi/10.1002 /asi.21422/epdf. Acesso em: 11 jul. 2017.

FLICK, Uwe. Desenho da pesquisa qualitativa. Porto Alegre: Artmed, 2009. GIL, Antonio Carlos. Métodos e técnicas de pesquisa social. São Paulo: Atlas, 2009.

GONZÁLEZ DE GOMEZ, Maria Nélida. Metodologia de pesquisa no campo da Ciência da Informação. Data Grama Zero Revista de Ciência da Informação, v. 1, n. 6, dez. 2000. Disponível em: http://www.dgz.org.br/dez00/Art_03.htm. Acesso em 10 jan. 2010.

LE COADIC, Yves-François. A ciência da Informação. Brasília: Briquet de Lemos/Livros, 1996.

MARTELETO, Regina Maria. Cultura Informacional: construindo o objeto informação pelo emprego dos conceitos de imaginário e campo social. Ciência da Informação, v. 24, n. 1, 1995. Disponível em: http://revista.ibict.br/index.php/ciinf/articl e/viewFile/535/487. Acesso em: 10 jan. 2010.

MARTINS, Gilberto de Andrade. Estudo de caso: uma estratégia de pesquisa. São Paulo: Atlas, 2008.
MINAYO, Maria Cecília de Souza (org.); DESLANDES, Suely Ferreira; GOMES, Romeu. Pesquisa social: teoria método e criatividade. Petrópolis: Vozes, 2009.

NÚÑEZ PAULA, Israel. Las necessidades de información y formación: perspectivas sociopsicológica e informacional. Acimed, Cuba, v. 12, n. 5, set./out. 2004. Disponível em:

http://bvs.sld.cu/revistas/aci/vol12_5_04/a ci04504.htm. Acesso em: 10 jan. 2010.

PINHEIRO, Lena Vânia Ribeiro. Usuários informação: o contexto da ciência e da tecnologia. Rio de Janeiro: IBICT, 1982. Disponível em: http://biblioteca.ibict.br/phl8/anexos/PINH EIROusuarios.pdf. Acesso em: 1 abr. 2010.

SAVOLAINEN, Reijo. Information behavior and information practice: reviewing the "umbrella concepts" of information-seeking studies. Library Quarterly, Chicago, v. 77, n. 2, p. 109-132, 2007.

YIN, Robert K. Estudo de caso: planejamento e métodos. Porto Alegre: Bookman, 2005. 